\title{
VARIÂNCIA GENÉTICA DE AÇÚCARES REDUTORES E MATÉRIA SECA E SUAS CORRELAÇÕES COM CARACTERÍSTICAS AGRONÔMICAS EM BATATA ${ }^{1}$
}

\author{
ADRIANA TOURINHO SALAMONI ${ }^{2}$, ARIONE DA SILVA PEREIRA ${ }^{3}$, JUDITH VIÉGAS ${ }^{4}$, \\ ÂNGELA DINIZ CAMPOS ${ }^{5}$ e CARLA SIMONE DE ALMEIDA CHALÁ
}

\begin{abstract}
RESUMO - O objetivo deste trabalho foi estimar os componentes de variância e herdabilidade relativos ao teor de açúcares redutores e à matéria seca, e suas correlações com algumas características agronômicas em batata (Solanum tuberosum L.). Foram utilizados quarenta clones de batata escolhidos aleatoriamente do Programa de Melhoramento Genético da Embrapa-Centro de Pesquisa Agropecuária de Clima Temperado. Os experimentos de campo foram conduzidos no outono e na primavera de 1996, em Pelotas, RS. Os teores de açúcares redutores e de matéria seca foram analisados após o armazenamento dos tubérculos em câmara fria $\left(5 \pm 1^{\circ} \mathrm{C}\right)$. As variâncias genéticas relativas a açúcares redutores e a matéria seca foram moderadas, e as variâncias dos erros, altas, proporcionando valores de herdabilidade relativamente baixos. O teor de açúcares redutores foi positivamente correlacionado com a maioria das características agronômicas, e negativamente correlacionado com o teor de matéria seca. As correlações entre a matéria seca e as características agronômicas foram baixas e não-significativas.
\end{abstract}

Termos para indexação: Solanum tuberosum, herdabilidade, processamento, genética quantitativa.

\author{
VARIANCE OF GENETIC REDUCING SUGARS AND DRY MATTER \\ AND THEIR CORRELATIONS WITH AGRONOMIC TRAITS IN POTATOES
}

\begin{abstract}
The objective of this research was to estimate the components of the variance and heritability relating to reducing sugars content and to dry matter, and their correlations with some agronomic traits of potato (Solanum tuberosum L.). Forty potato clones randomly chosen by the Embrapa-Centro de Pesquisa Agropecuária de Clima Temperado Breeding Program were used. The field experiments were carried out in the fall and in the spring of 1996, in Pelotas, RS, Brazil. Sugar and dry matter content were analyzed after storing tubers in cold chamber $\left(5 \pm 1^{\circ} \mathrm{C}\right)$. Genetic variances relating to reducing sugars and to dry matter content were moderate, and error variances were high, providing relatively low heritability values for both traits. The reducing sugar content was positively and significantly correlated with most of the agronomic traits and negatively correlated with dry matter content. The correlations between dry matter and agronomic traits were low and not significant.
\end{abstract}

Index terms: Solanum tuberosum, heritability, processing, quantitative genetics.

${ }^{1}$ Aceito para publicação em 20 de julho de 1999.

${ }^{2}$ Eng. Agrôn., M.Sc., Escola Agrotécnica Federal de Rio do Sul, Caixa Postal 441, CEP 89160-000 Rio do Sul, SC.

${ }^{3}$ Eng. Agrôn., Ph.D., Embrapa-Centro de Pesquisa Agropecuária de Clima Temperado (CPACT), Caixa Postal 403, CEP 96001-970 Pelotas, RS. E-mail: arione@cpact.embrapa.br

${ }^{4}$ Biól., Dra., Dep. de Zoologia e Genética, Universidade Federal de Pelotas (UFPEL), Caixa Postal 354, CEP 96001-970 Pelotas, RS.

${ }^{5}$ Eng. Agrôn., M.Sc., CPACT.

${ }^{6}$ Biól., M.Sc., UFPEL.

\section{INTRODUÇÃO}

Com o aumento do consumo de batata na forma processada, as indústrias têm demandado novas cultivares, que proporcionem um produto final de boa qualidade. No Brasil, o tipo industrializado predominante é o chips (Silva, 1991).

Os principais fatores condicionantes da qualidade dos tubérculos para processamento são o conteúdo de açúcares redutores (glicose e frutose) e o 
teor de matéria seca (Loiselle et al., 1990). Os açúcares redutores são importantes, pois reagem com aminoácidos e proteínas durante a fritura dos chips, numa reação chamada de Maillard, e provocam o escurecimento do produto e a não-aceitação pelo consumidor (Cunningham \& Stevenson, 1963; Talburt et al., 1975). Conforme Silva (1991), o teor de matéria seca dos tubérculos determina a absorção de óleo durante a fritura, a textura, o sabor e o rendimento de chips.

A qualidade do chips é influenciada por fatores genéticos e ambientais, tais como a temperatura de armazenamento dos tubérculos. Tanto temperaturas altas quanto baixas provocam acúmulo de açúcares, especialmente, de sacarose, glicose e frutose (Stevenson et al., 1954; Pressey, 1969). Verma et al. (1974) relataram maior acúmulo de açúcares, principalmente redutores sob baixa temperatura. De acordo com alguns autores (Habib \& Brown, 1956; Verma et al., 1974; Uppal \& Verma, 1990), há diferenças genéticas entre clones na acumulação de açúcares relacionada à temperatura de armazenamento da batata. Conforme Pereira et al. (1994), há pouca informação sobre os parâmetros genéticos que influenciam o acúmulo dos açúcares redutores nos tubérculos estocados sob baixa temperatura.

Este trabalho teve como objetivo estimar componentes de variância e herdabilidade do teor de açúcares redutores e matéria seca e suas correlações com algumas características agronômicas em batata.

\section{MATERIAL E MÉTODOS}

Quarenta clones de batata (Solanum tuberosum L.) foram escolhidos aleatoriamente entre os utilizados pelo Programa de Melhoramento Genético da Embrapa-Centro de Pesquisa Agropecuária de Clima Temperado, em Pelotas, RS. Foram utilizadas como testemunhas as cultivares Baronesa, Macaca, Monte Bonito, BR-3, Atlantic e o clone C-1582-25-90, por sua diversidade quanto às características estudadas.

Os experimentos de campo foram conduzidos no outono e na primavera de 1996, em Pelotas, RS. O solo utilizado, classificado como Podzólico Vermelho-Amarelo, foi adubado com $2.000 \mathrm{~kg} \mathrm{ha}^{-1}$ da fórmula NPK (12-25-15). O delineamento experimental usado foi o de blocos aumentados. As testemunhas foram repetidas quatro vezes, num delineamento em blocos casualizados, e os clones não fo- ram repetidos: foram distribuídos ao acaso, nos blocos do experimento. Cada bloco foi constituído por 20 parcelas, e cada uma, composta por cinco tubérculos.

As plantas de cada parcela foram avaliadas visualmente em relação ao vigor e à maturidade das plantas. O vigor foi avaliado 92 e 76 dias após o plantio, no outono e na primavera, respectivamente, utilizando-se uma escala de 1 a 5 ( 1 = pouco vigorosa, 5 = muito vigorosa). A maturidade foi avaliada 92 e 108 dias após o plantio de outono, e 76 e 90 dias após o plantio de primavera, de acordo com o grau de senescência das plantas $(1=$ precoce, $5=$ tardia $)$.

A produção de cada parcela foi classificada, contada e pesada. Foram obtidos os dados de produção de tubérculos comerciais (diâmetro transversal maior que $45 \mathrm{~mm}$ ), produção total de tubérculos, em $\mathrm{g}_{\text {parcela }}{ }^{-1}$, número de tubérculos comerciais, número total de tubérculos e peso médio dos tubérculos.

Após o armazenamento dos tubérculos em câmara fria $\left(5 \pm 1^{\circ} \mathrm{C}\right)$ durante 71 dias, foi quantificado o teor de açúcares redutores. Os tubérculos foram fatiados, secos em estufa, e moídos. Esta análise foi realizada conforme o método de Somogyi, modificado por Nelson (1944). A leitura do teor dos açúcares foi feita em espectrofotômetro UV-1601 PC, marca Shimadzu, em comprimento de onda para $510 \mathrm{~nm}$. A matéria seca foi determinada por secagem em estufa com circulação de ar, à temperatura de $105^{\circ} \mathrm{C}$, até peso constante.

A análise de variância dos dados combinados dos dois períodos de cultivo foi realizada no tocante aos clones e às testemunhas. Os dados das cultivares-testemunhas foram analisados com vistas à estimativa do erro experimental, a ser usado para testar o quadrado médio da interação clone $\mathrm{x}$ período de cultivo.

A estimativa dos componentes da variância foi obtida a partir dos quadrados médios calculados, e os quadrados médios esperados foram baseados no modelo de efeito casual de períodos e clones.

O intervalo de confiança da herdabilidade ( $\alpha=10 \%$ ) foi estimado com base em Tai (1989).

As correlações fenotípicas e genéticas entre as características de qualidade e as características agronômicas foram obtidas a partir das variâncias e covariâncias.

\section{RESULTADOS E DISCUSSÃO}

A análise da variância dos dados combinados dos dois períodos de cultivo (Tabela 1) revelou diferenças significativas $(\mathrm{P}<0,05)$, entre os clones, quanto aos açúcares redutores e à matéria seca.

Estes resultados indicam a existência de variação genética quanto às duas características e a pos- 
sibilidade de realizar seleção para o melhoramento da população estudada. A interação clone x período de cultivo, testada com o quadrado médio do erro da análise das testemunhas, foi significativa somente no tocante à matéria seca, o que indica que houve resposta diferente da dos clones aos períodos de cultivo. Portanto, é recomendável selecionar com vistas a matéria seca com base na avaliação nos dois períodos de cultivo.

Os componentes de variância (Tabela 2) referentes aos açúcares redutores e à matéria seca evidenciaram variância genética moderada quanto a ambas as características. Isto possivelmente ocorreu porque os genitores utilizados nos cruzamentos não foram muito divergentes em relação a estas caracte-

TABELA 1. Análise da variância de características de qualidade de 40 clones de batata cultivados no outono e primavera de 1996. Pelotas, RS.

\begin{tabular}{lrcc}
\hline Causas da variação & \multicolumn{2}{c}{ GL } & \multicolumn{2}{c}{ Quadrado médio } & Valor de P \\
\hline & \multicolumn{3}{c}{ Açúcares redutores (\%) } \\
Clone (C) & 39 & 0,79 & 0,02 \\
Período (P) & 1 & 1,15 & 0,10 \\
C x P & 39 & 0,40 & 0,24 \\
Erro $^{1}$ & & 0,31 & \\
\hline & & \multicolumn{2}{c}{ Matéria seca (\%) } \\
Clone (C) & 39 & 13,54 & $<0,01$ \\
Período (P) & 1 & 562,54 & $<0,01$ \\
C x P & 39 & 6,05 & $<0,01$ \\
Erro $^{1}$ & & 4,18 & \\
\hline
\end{tabular}

1 Quadrado médio da análise da variância das testemunhas. rísticas. A variância do erro foi superior à dos demais componentes de variância nas duas características. Neele \& Louwes (1989) e Pereira et al. (1994) também observaram variâncias genéticas bem superiores às variâncias do erro, em experimentos com populações de seedlings e de clones, respectivamente, usando cultivares-testemunhas para estimar a variância do erro.

A eficiência da seleção depende da magnitude da herdabilidade. Em culturas de propagação assexuada tal como batata, a combinação de fatores genéticos não varia de geração para geração. Portanto, a herdabilidade no sentido amplo deveria ser estimada num programa de melhoramento (Tai \& Young, 1984). As estimativas de herdabilidade relativas ao teor de açúcares redutores e de matéria seca neste estudo (Tabela 2) foram relativamente baixas, principalmente em decorrência dos valores elevados da variância do erro. O valor da herdabilidade quanto aos açúcares redutores é menor que o estimado por outros autores (Grassert et al., 1984; Pereira et al., 1994). Quanto ao teor de glicose, Chitsaz (1983) relatou herdabilidade baixa, de valor 0,21. É sabido que estimativas de herdabilidade são únicas, dependendo da diversidade genética do material testado e de fatores ambientais (Falconer, 1989).

Os valores da herdabilidade quanto à matéria seca estimados no presente estudo foram comparáveis aos encontrados por Cunningham \& Stevenson (1963). Entretanto, foram inferiores às estimativas de herdabilidade com base na média de progênies (Maris, 1969; Neele \& Louwes, 1989).

Os níveis de variância genética e de herdabilidade estimados indicam que seriam razoáveis as respostas de seleção para baixo teor de açúcares redutores e alto teor de matéria seca. Conforme Simmonds

TABELA 2. Estimativas dos componentes da variância genética $\left(\sigma^{2}{ }_{G}\right)$, interação genótipo $x$ período de cultivo $\left(\sigma_{G A}^{2}\right)$ e erro $\left(\sigma_{E}^{2}\right)$ e da herdabilidade $\left(h^{2}\right)$ relativas a características de qualidade de batata cultivada no outono e primavera de 1996. Pelotas, RS.

\begin{tabular}{|c|c|c|c|c|}
\hline \multirow[t]{2}{*}{ Característica } & \multicolumn{3}{|c|}{ Componentes da variância } & \multirow[t]{2}{*}{$\mathrm{h}^{2}\left(\mathrm{IC}^{2}\right)$} \\
\hline & $\sigma_{\mathrm{G}}^{2} \pm \mathrm{dp}^{1}$ & $\sigma_{\mathrm{GA}}^{2} \pm \mathrm{dp}$ & $\sigma_{E}^{2} \pm d p$ & \\
\hline Açúcares redutores & $0,19 \pm 0,10$ & $0,09 \pm 0,12$ & $0,31 \pm 0,08$ & $0,32(0,07 ; 0,54)$ \\
\hline Matéria seca & $3,74 \pm 1,64$ & $1,88 \pm 1,70$ & $4,18 \pm 1,04$ & $0,38(0,13 ; 0,58)$ \\
\hline
\end{tabular}

1 Desvio-padrão

2 Intervalo de confiança 
(1979), a resposta à seleção depende da média da população, da intensidade de seleção, da herdabilidade e da variância genética.

As correlações fenotípicas e genéticas de açúcares redutores e matéria seca (Tabela 3 ) com características agronômicas, em geral, foram baixas $(r<0,50)$, sendo que as genéticas foram superiores às fenotípicas.

As correlações genéticas entre teor de açúcares redutores e número de tubérculos comerciais, produção de tubérculos (comercial e total) e peso médio de tubérculos, foram positivas e significativas, enquanto a correlação entre açúcares redutores e matéria seca foi negativa. De acordo com Iratani \& Weller (1976), batatas com alto peso específico acumulam menores teores de açúcares durante a permanência no armazém. Portanto, a seleção para baixo teor de açúcares redutores resultaria em clones com maior conteúdo de matéria seca, porém com menor produção (comercial e total) e peso médio do tubérculo.

Os coeficientes de correlação entre o teor de matéria seca e as características agronômicas foram baixos e não-significativos, o que indica reduzida associação genética entre estas características. Portanto, a seleção para alto teor de matéria seca afetaria pouco a produção de tubérculos, bem como a maturidade e o vigor das plantas da população de clones selecionada.

TABELA 3. Correlações fenotípicas $\left(r_{F}\right)$ e genéticas $\left(r_{G}\right)$ entre características de qualidade e características agronômicas de batata cultivada no outono e primavera de 1996. Pelotas, RS.

\begin{tabular}{llccc}
\hline \multirow{2}{*}{ Característica agronômica } & \multicolumn{4}{c}{ Características de qualidade } \\
\cline { 2 - 5 } & \multicolumn{3}{c}{ Açúcares redutores } & \multicolumn{2}{c}{ Matéria seca } \\
\cline { 2 - 5 } & $\mathrm{r}_{\mathrm{F}}$ & $\mathrm{r}_{\mathrm{G}}$ & $\mathrm{r}_{\mathrm{F}}$ & $\mathrm{r}_{\mathrm{G}}$ \\
\hline Maturidade & 0,07 & 0,06 & 0,06 & 0,14 \\
Vigor & 0,13 & 0,28 & 0,01 & 0,17 \\
$\mathrm{~N}^{9}$ tubérculos comerciais & $0,37^{*}$ & $0,62^{*}$ & $-0,19$ & $-0,28$ \\
№ total de tubérculos & 0,04 & $-0,27$ & 0,01 & $-0,01$ \\
Prod. tubérculos comerciais & $0,32^{*}$ & $0,75^{*}$ & $-0,20$ & $-0,27$ \\
Prod. total de tubérculos & 0,25 & $0,46^{*}$ & $-0,15$ & $-0,21$ \\
Peso médio de tubérculos & 0,14 & $0,63^{*}$ & $-0,12$ & $-0,15$ \\
Matéria seca & $-0,25$ & $-0,72^{*}$ & - & - \\
\hline
\end{tabular}

* Significativo a $5 \%$ de probabilidade.

\section{CONCLUSÕES}

1. As variâncias genéticas referentes aos açúcares redutores e à matéria seca são moderadas, ao passo que as variâncias dos erros são altas.

2. Os valores de herdabilidade relativas aos açúcares redutores e à matéria seca são relativamente baixos.

3. O teor de açúcares redutores é positivo e significativamente associado com a maioria das características agronômicas, e negativamente, com o teor de matéria seca.

4. Não há correlação entre o teor de matéria seca e as características agronômicas.

\section{AGRADECIMENTOS}

À equipe de apoio ao Programa de Melhoramento Genético de Batata e à funcionária do Laboratório de Fisiologia Vegetal, Eliana Mariete da Luz Silveira, da Embrapa-Centro de Pesquisa Agropecuária de Clima Temperado, pelo auxílio prestado durante a execução deste trabalho.

\section{REFERÊNCIAS}

CHITSAZ, M. Inheritance of factors affecting quality of processed potatoes (Solanum tuberosum group tuberosum L.). Fargo : North Dakota State University, 1983. 54p. Ph.D. Thesis

CUNNINGHAM, C.E.; STEVENSON, F.J. Inheritance of factors affecting potato chip color and their association with specific gravity. American Potato Journal, Orono, v.40, p.253-265, 1963.

FALCONER, D.S. Introduction to quantitative genetics. 3.ed. New York : Longman Scientific and Technical, 1989. 438p.

GRASSERT, V.; VOGEL, J.; BARTEL, W. Einfluss der sorte und einiger Umweltfaktoren auf die Neigung von Kartoffelknollen zur Zuckerbildung während einer mehrmonatigen Lagerung bei $4{ }^{\circ} \mathrm{C}$. Potato Research, Wageningen, v.27, p.365-372, 1984.

HABIB,A.T;; BROWN, H.D. Factors influencing the color of potato chips. Food Technology, Chicago, v.10, p.332-336, 1956. 
IRATANI, W.M.; WELLER, L.D. Relationship of specific gravity to sugar accumulation in stored Norgold and Russet Burbank potatoes. American Potato Journal, Orono, v.53, p.57-65, 1976.

LOISELLE, F.; TAI, G.C.C.; CHRISTIE, B.R. Genetic components of chip color evaluated after harvest, cold storage and reconditioning. American Potato Journal, Orono, v.67, p.633-646, 1990

MARIS, B. Studies on maturity, yield, under weight water and some other characters of potato progenies. Euphytica, Dordrecht, v.18, p.297-319, 1969.

NEELE,A.E.F.; LOUWES, K.M. Early selection for chip quality and dry matter content in potato seedling populations in greenhouse or screenhouse. Potato Research, Wageningen, v.32, p.293-300, 1989.

NELSON, N.A. A photometric adaptation of Somogyi method for the determination of glucose. Journal of Biological Chemistry, Bethesda, v.153, p.375-380, 1944.

PEREIRA, A. da S.; TAI, G.C.C.; YADA, R.Y.; COFFIN, R.H.; SOUZA-MACHADO, V. Potential for improvement by selection for reducing sugar content after cold storage for three potato populations. Theoretical and Applied Genetics, Berlin, v.88, p.678-684, 1994.

PRESSEY, R. Role of invertase in the accumulation of sugars in cold-stored potatoes. American Potato Journal, Orono, v.46, p.291-297, 1969

SILVA, A.C.F. da. Batata: alguns aspectos importantes Agropecuária Catarinense, Florianópolis, v. 4 p.38-41, 1991.
SIMMONDS, N.W. Principles of crop improvement New York : Longman, 1979. 408p.

STEVENSON, F.J.;AKELEY, R.V.; MCLEAN, J.G. Potato utilization in relation to variety (heredity) and environment. American Potato Journal, Orono, v.31, p.327-340, 1954.

TAI, G.C.C. A new procedure to construct confidence intervals for genotypic variance and expected response to selection. Genome, Ottawa, v.32, p.307-308, 1989.

TAI, G.C.C.; YOUNG, D.A. Early generation selection for important agronomic characteristics in a potato breeding population. American Potato Journal, Orono, v.61, p.419-434, 1984.

TALBURT, W.F.; SCHWIMMER, S.; BURR, H.K Structure and chemical composition of the potato tuber. In: TALBURT, W.F.; SMITH, O. (Ed.). Potato processing. 3.ed. Westport : AVI, 1975. p.11-42.

UPPAL, D.S.; VERMA, S.C. Changes in sugar content and invertase activity in tubers of some Indian potato varieties stored at low temperature. Potato Research, Wageningen, v.33, p.119-123, 1990.

VERMA, S.C.; SHARMA, T.R.; VERMA, S.M. Effects of extended high-temperature storage on weight losses and sugar content of potato tubers. Indian Journal of Agricultural Science, New Delhi, v.44, p.702-706, 1974. 